\title{
Deposition Formation Effect of Biodiesel in a Diesel Engine Fuel Injector
}

\author{
Sajjad Bhangwar ${ }^{1}$, Aijaz Abbasi ${ }^{1}$, Liaquat Ali Memon ${ }^{1}$, Sher Muhammad Ghoto ${ }^{1}$, Azhar Hussain Shah ${ }^{1}$, \\ Muhammad Ramzan Luhur ${ }^{1}$ \\ ${ }^{1}$ Mechanical Engineering Department, Quaid-e-Awam University of Engineering Science and Technology Nawabshah-67480, \\ Pakistan \\ *Corresponding Author:- aijaz-abbasi@quest.edu.pk
}

\begin{abstract}
To establish a long-term sustainability of biodiesel to fulfill the quest for renewable fuel resources for the countries has low or no fossil fuels reserves. The energy resource meets to its limited capacity, alternative new energy resources must be explored such as the introduction of biodiesel as an alternative energy resources of petroleum products. The present research work is a 90-hour long-term endurance test performed with B30 sample (biodiesel 30\% + 70\% diesel) fueled with modified investigation performance, sound pressure level and engine durability. Special attention has been given to certain phenomena affecting the life of the engine, the formation of deposits and its performance. Experimental results of this research work demonstrated that the modified diesel engine could be efficiently performed with the B30 fuel sample.
\end{abstract}

Key words: Biodiesel, renewable fuel, pressure, engine performance, and energy.

\section{INTRODUCTION}

If the global supply of fossil fuels is declined, then the price of crude oil will be increased. Therefore, it would not be feasible to plethora use of fuel oil goods such as gas or gasoline, etc. The researchers of the world trying to find out the suitable alternate fuel which produces from renewable resource. Scientists and research centers are seeking to come up with a bio-fuel alternative. Biodiesel and its associated blends are classified in a renewable and sustainable fuels [1]. Since the properties of these fuels are close to those of diesel [2]. Biofuels from renewable resources are known as biomass. Biofuels are obtained from plants and animal waste. Biomass is derived from wastewater and animal waste, the gas that generated by the wood gasification cycle which is known as pyrolysis ethanol plants [3]. Biodiesel products are derived from several materials, such as recycled cooking oil, palm oil and animal fats, including glycerides. Vegetable oil used in plethora of glycoside forms [4]. The method that transforms vegetable oil to biodiesel is called transesterification. According to the American Society of Testing Substance Norm, the biodiesel is classified as mono- alkyl esters that designated as B100. Biodiesel products reduced greenhouse gas (GHG) emissions and nearly 50 percent of normal life cycle (GHG) pollution [5]. Biodiesel provides a lot of miscible of fossil petrol. Biodiesel mixed with petrol to improve fuel efficiency. The not-similar properties are like jet fuel. The physicochemical properties of the fuel can influence engine parameters of various fuel ratios of biodiesel blended with diesel fuel [6], [7]. As load rises, actual fuel usage decreases and smoke rises with large fuel gas ratios. The brake specific fuel consumption (BSFC) decreases at lower load due to decreased mechanical performance [8]. Some researchers are exploring the usage of biodiesel in a compression ignition engine that consumes less power due to its lower calorific content [9], [10]. The high density and viscosity of biodiesel, the basic fuel intake of the brakes is improved relative to petrol [11]. Biodiesel requires a stronger combustion cycle owing to its low oxygen content. Carbon deposits described as a range of mixtures made up of carbon particles. Carbonaceous mixtures (soot) and oxygenated resinous organic compounds blend as mixtures deposit frequently accumulate some engine parts in the combustion chamber, such as piston, intake and exhaust valves, cylinder head and the injector tip [12], [13]. Due to the development of deposition on nozzle injector that slows movement of injector which has a maximal effect at short injection time and in high load it impacts intensity [14]. At high injection pressure and maximum load, the volume of injection decreased by the lack of control on the internal injector [15]. However, it improves the compression of engine in creation of exhaust layer in combustion chamber and decreases the amount of clearance [16]. The brake specific fuel consumption (BSFC) is the brake power of the heat engine as a part of heat supplied by fuel. The brake specific fuel consumption (BSFC) variation depends on load of engine, the speed and blending ratio of biodiesel. Higher density and lower fuel heating values allow higher fuel mass to a certain energy efficiency from engine [17], [18]. Density and calorific value have been found to have a significant effect on the degree of unsaturation [19]. In this research, two fuel samples were used, such as D100 and B30. Brake specific fuel intake B30 was found higher than D100 due to its high oxygen content 
and high calorific values which gives lower heating performance.

\section{METHODOLOGY}

The endurance test on each fuel sample has been carried out for 90 hours in this research. During the evaluation, the engine performance and the noise level were assessed. The fuel properties were initially tested on the ASTM standard. Finally, the deposition of the injector on a different fuel was analyzed using the SEM and EDX methods. Engine durability tested at constant loads of $9.8 \mathrm{~N}-\mathrm{m}$ and $1400 \mathrm{rpm}$. The engine was running on diesel fuel for 90 hours at first stage. The fuel injector was replaced Jayshree Pawar et al., International Journal of Emerging Trends in Engineering Research, 9(8), August 2021, 1051 1056for deposition analysis after completion of 90 hours duration. However, the engine started for heat-up or warmup on diesel fuel for 20 minutes then it was operating at steady load and speed. The purpose of this study is to assess the atomic deposition of the injector. In addition, two injectors have been checked. Microscopic and visual examination was conducted at various positions of the nozzle. Upon completion of engine running of 90-hour, the deposition of the aromatic compound elements was studied using SEM and EDX methods. The engine efficiency and noise pollution level check experiments were carried out at Mechanical Engineering Laboratories of Quaid-e-Awam University of Engineering Science and Technology Nawabshah, Pakistan. The two fuel samples were used in this research work to evaluate the degree of output and noise pollution with constant rpm (1400rpm) and variable load (0.1 to 1.5 ) on an engine.

\section{RESULTS AND DISCUSSIONS}

It was found that the rise of fuel consumption at the same power output when increasing percentage of biodiesel blend and calorific value. The deviation of BTE was observed in this research work as shown in Figure 1 and Figure 2. The thermal brake efficiency of D100 improved from $0.1 \mathrm{KW}$ to $1.5 \mathrm{KW}$ of the engine. The increase percentage of oxygen content are improving the faster combustion processes. Various fuel compositions of diesel and biodiesel have been used in this research work on noise emission levels of the engine. The blend of biodiesel fuel generates low noise emissions compared to diesel fuel. The noise level examined from center, back and left sides in this research study. The front side of engine created more noise pollution as compared to the back and left sides as seen in Figure 3, Figure 4, and Figure 5. However, B30 sample of fuel has a lower sound pressure because of high oxygen level than diesel fuel. The cetane number is an important parameter to be known as the delay of the ignition. Cetane number plays an important role during compression ignition. The shortest ignition delay occurs when the cetane number is higher [20]. The engine ran for 90-hours on different fuel samples such as
B30 and D100. After completion of the 90-hours of engine running the scanning of electron microscopy (SEM) test was carried out as shown in Figure 7 and Figure 9. The energy dispersive X-ray spectroscopy was performed at different locations of the injector surface as shown in Figure 6 and Figure 8 which are illustrating the deposition occurred at different locations of injectors. The compositions of elements are the bland of carbon and oxygen. Carbon created by two processes such as, the separation of hydrocarbons into hydrogen and carbon, other is the polymerization of the hydrocarbon product. D100 and B 30 generated 56\% and $61 \%$ of carbon as shown in the Figure 6 to Figure 9, respectively. The oxygen element deposition found in D100 and $\mathrm{B} 30$ are $40.04 \%$ and $38.72 \%$, respectively. D100 was observed on the $1.44 \%$ Sulphur, $0.97 \%$ calcium, $0.58 \%$ iron and $0.54 \%$ zinc. However, B30 was observed at $1.16 \%$ Sulphur and $0.62 \%$ iron. The higher distillation temperature contributes to an improvement in development of deposition on injector sheet.

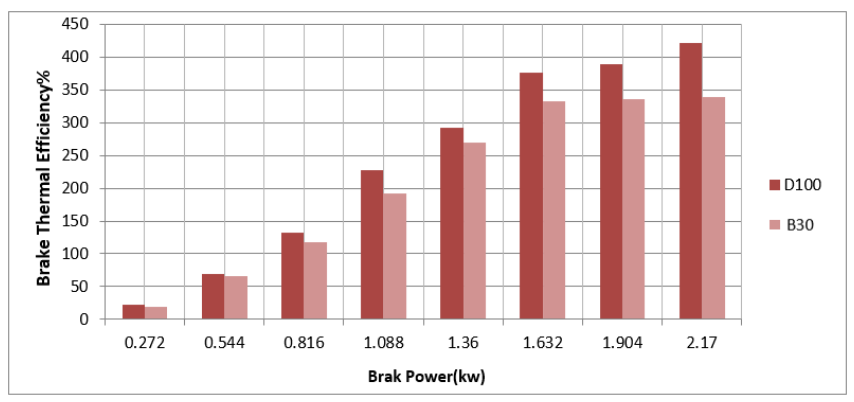

Figure 1: Brake thermal efficiency

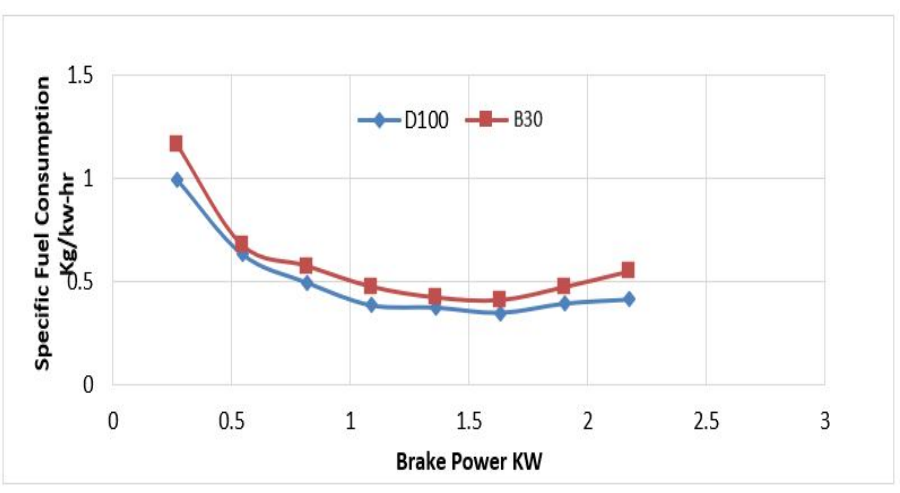

Figure 2:Break specific fuel consumption (bsfc) cooperation analysis. 


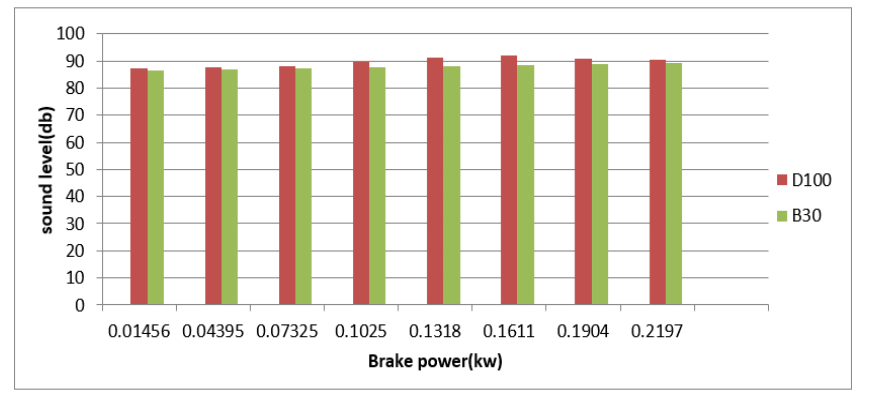

Figure 3: Sound pressure level at front positions

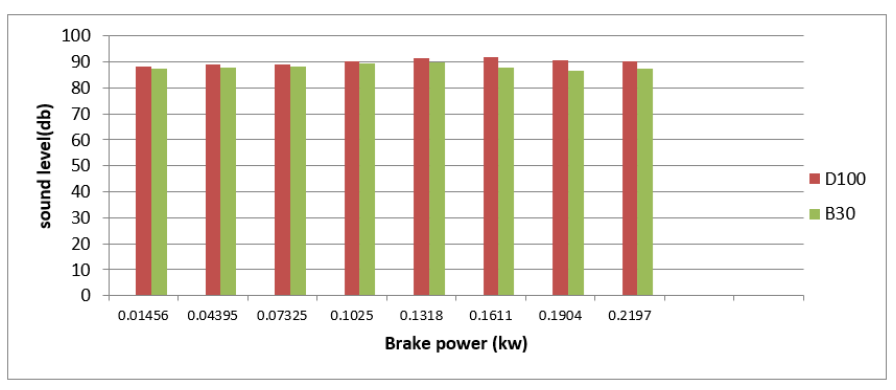

Figure 4: Sound pressure level at back position

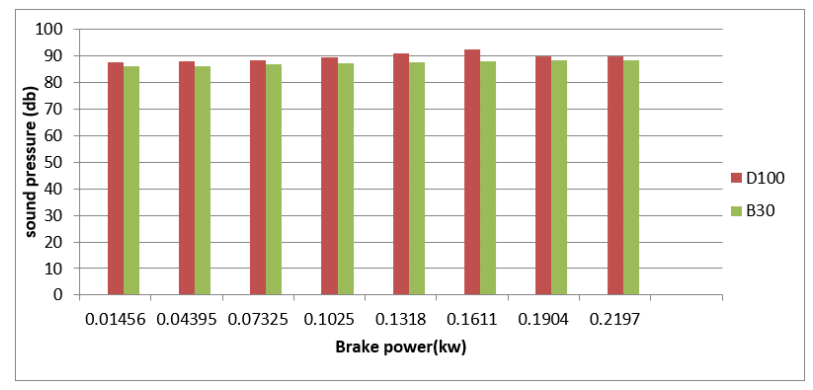

Figure 5: Sound pressure level at left position

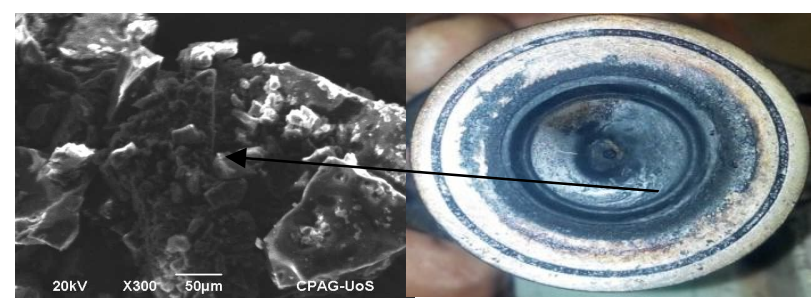

Figure 6: Energy Dispersive X-ray spectroscopy for D100.

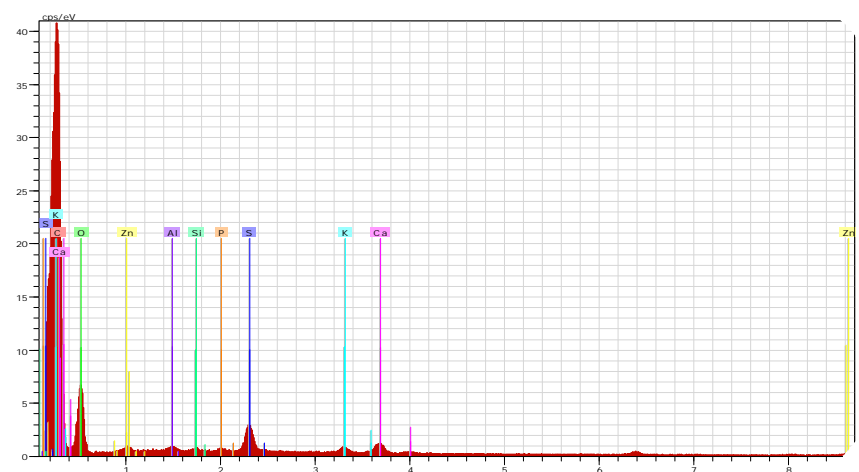

Figure 7: 90-hour scanning electron microscopy (SEM) test for D100.

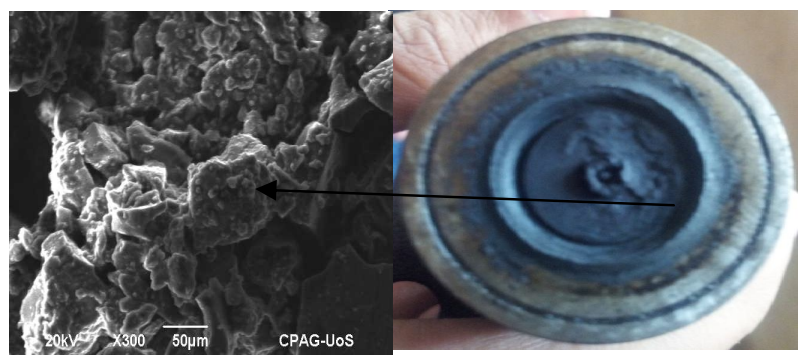

Figure 8: Energy Dispersive X-ray spectroscopy for B30

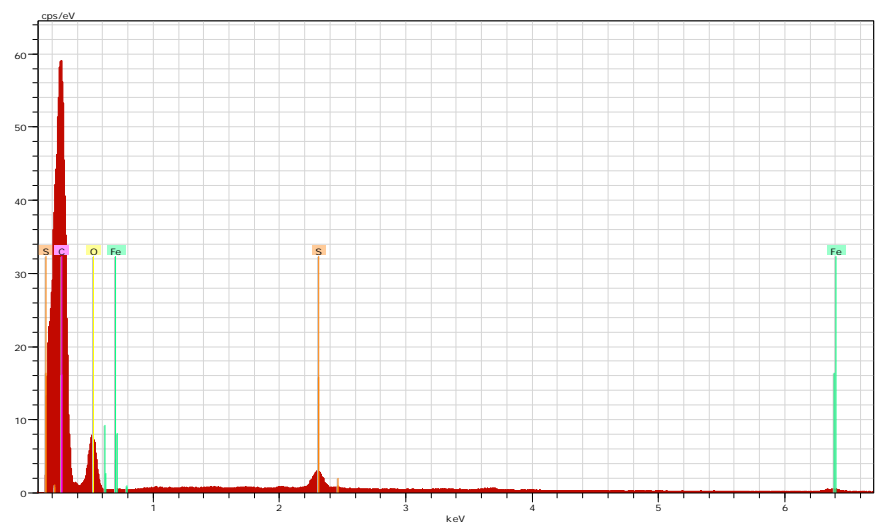

Figure 9: 90-hour scanning electron microscopy (SEM) test for B30.

\section{CONCLUSION}

This research study consisted of engine performance, engine sound pressure level emission and engine endurance test on two fuel samples of D100 and B30 which were analyzed on experimental results. As compare to D100, the B30 has less heating value and higher oxygen level compared to diesel fuel. However kinematic viscosity, cetane number, flash point, fire point and specific gravity are higher in B30. The brake thermal efficiency of diesel is higher in D100. However, the results of sound pressure level of D100 is higher due to its higher heating value, less cetane number, low lubricity, and low oxygen contents. The endurance test was carried out for 90-hours with constant rpm and constant load of running on an engine. During endurance test, higher deposition of carbon and other aromatic compounds were investigated in B30 due to unsaturated double bond.

\section{ACKNOWLEDGEMENT}

The authors are very grateful to Quaid-e-Awam University of Engineering Science and Technology Nawabshah, Pakistan, for their assistance in this research work. 
Sajjad Bhangwar et al., International Journal of Emerging Trends in Engineering Research, 9(8), August 2021, 1057 - 1060

\section{REFERENCES}

1. Lourentius, Suratno, Setiyadi, Albert Gunadhi, David Reinaldo, and Gunawan Andri Wijaya. "Bio-oil from pyrolysis of pine fruit as renewable alternative energy: The effect of catalyst zeolite to pine fruit mass ratio and temperature on yield." In AIP Conference Proceedings, vol. 2114, no. 1, p. 060017. AIP Publishing LLC, 2019.

2. Paul, Gaurav, Ambarish Datta, and Bijan Kumar Mandal. "An experimental and numerical investigation of the performance, combustion and emission characteristics of a diesel engine fueled with jatropha biodiesel." Energy Procedia 54 (2014): 455-467.

3. Kumaraswamy, A., and B. Durga Prasad. "Performance analysis of a dual fuel engine using LPG and diesel with EGR system." Procedia engineering 38 (2012): 2784-2792.

4. Jain, Siddharth, and Mahendra Pal Sharma. "Oxidation stability of blends of Jatropha biodiesel with diesel." Fuel 90, no. 10 (2011): 3014-3020.

5. Kim, Seungdo, and Bruce E. Dale. "Environmental aspects of ethanol derived from no-tilled corn grain: nonrenewable energy consumption and greenhouse gas emissions." Biomass and bioenergy 28, no. 5 (2005): 475-489.

6. Christopher, M., and R. Sabarish. "Emission analysis of a single cylinder Di engine running on biodiesel blend as fuel." Middle East Journal of Scientific Research 20, no. 6 (2014): 681-684.

7. Piccolo, Antonio. Aquatic Biofuels: New Options for Bioenergy. Universal-Publishers, 2010.

8. Arifin, Y. M. "Diesel and Bio-diesel Fuel Deposits on a Hot Wall Surface." A Thesis, Department of Mechanical System Engineering Gunma University Japan (2009).

9. Dudley, Bob. "BP statistical review of world energy." BP Statistical Review, London, UK, accessed Aug 6 (2018): 2018.

10. Hoekman, S. Kent, Amber Broch, Curtis Robbins, Eric Ceniceros, and Mani Natarajan. "Review of biodiesel composition, properties, and specifications." Renewable and sustainable energy reviews 16, no. 1 (2012): 143-169.

11. Alptekin, Ertan, and Mustafa Canakci. "Characterization of the key fuel properties of methyl ester-diesel fuel blends." Fuel 88, no. 1 (2009): 75-80.

12. Taylor, Andrew B., Derek P. Moran, Arthur J. Bell, Neale G. Hodgson, Ian S. Myburgh, and Johan J. Botha. Gasoline/alcohol blends: exhaust emissions, performance and burn-rate in a multi-valve production engine. No. 961988. SAE Technical Paper, 1996.

13. Pulkrabek, Willard W. "Engineering fundamentals of the internal combustion engine." (2004): 198-198.

14. Karabektas, Murat. "The effects of turbocharger on the performance and exhaust emissions of a diesel engine fuelled with biodiesel." Renewable Energy 34, no. 4 (2009): 989-993.
15. Hazar, Hanbey. "Effects of biodiesel on a low heat loss diesel engine." Renewable Energy 34, no. 6 (2009): 1533-1537.

16. Guan, L., X. L. Feng, G. Xiong, and J. A. Xie. "Application of dielectric spectroscopy for engine lubricating oil degradation monitoring." Sensors and Actuators A: Physical 168, no. 1 (2011): 22-29.

17. Mesfin, K. "Investigation of Alternative Locally Available Feedstock Sources for Biodiesel Production in Ethiopia" viz." R. communis, B. carinata, J. Curcas\& E. guineensis 24 (2008): 2300-2309.

18. Ye, Z., Q. Meng, H. P. Mohamadian, J. T. Wang, L. Chen, and L. Zhu. "Investigation of deposit formation mechanisms for engine in-cylinder combustion and exhaust systems using quantitative analysis and sustainability study." International Journal of Thermophysics 28, no. 3 (2007): 1056-1066.

19. Kalghatgi, Gautam T. "Deposits in gasoline engines-a literature review." SAE transactions (1990): 639-667.

20. Ullmann, Jörg, Marion Geduldig, Heinz Stutzenberger, Rinaldo Caprotti, and Graham Balfour. Investigation into the formation and prevention of internal diesel injector deposits. No. 2008-01-0926. SAE Technical Paper, 2008. 